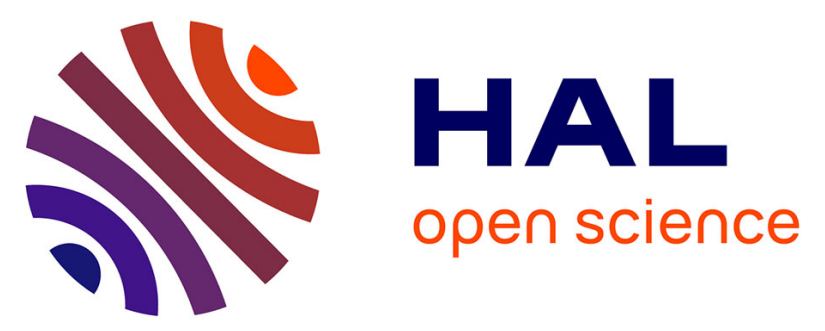

\title{
Fate of emerging and priority micropollutants during the sewage sludge treatment: Case study of Paris conurbation. Part 1: Contamination of the different types of sewage sludge
}

\author{
R. Mailler, J. Gasperi, Dominique Patureau, E. Vulliet, N. Delgenes, A.
}

Danel, S. Deshayes, V. Eudes, S. Guerin, R. Moilleron, et al.

\section{To cite this version:}

R. Mailler, J. Gasperi, Dominique Patureau, E. Vulliet, N. Delgenes, et al.. Fate of emerging and priority micropollutants during the sewage sludge treatment: Case study of Paris conurbation. Part 1: Contamination of the different types of sewage sludge. Waste Management, 2017, 59, pp.379-393. 10.1016/j.wasman.2016.11.010 . hal-01397727

\section{HAL Id: hal-01397727 \\ https://hal-enpc.archives-ouvertes.fr/hal-01397727}

Submitted on 4 Jul 2018

HAL is a multi-disciplinary open access archive for the deposit and dissemination of scientific research documents, whether they are published or not. The documents may come from teaching and research institutions in France or abroad, or from public or private research centers.
L'archive ouverte pluridisciplinaire HAL, est destinée au dépôt et à la diffusion de documents scientifiques de niveau recherche, publiés ou non, émanant des établissements d'enseignement et de recherche français ou étrangers, des laboratoires publics ou privés. 
Fate of emerging and priority micropollutants during the sewage sludge treatments: case study of Paris conurbation.

Part 1: Contamination of the different types of sewage sludges, condensed and centrifuged waters

R. Mailler ${ }^{1 *}$, J. Gasperi $^{1 *}$, D. Patureau ${ }^{2}$, E. Vulliet ${ }^{3}$, N. Delgenes ${ }^{2}$, A. Danel $^{2}$, S. Deshayes ${ }^{1,4}$, V. Eudes ${ }^{4}$, S. Guerin ${ }^{5}$, R. Moilleron ${ }^{1}$, G. Chebbo ${ }^{6}$ and V. Rocher ${ }^{5 *}$

${ }^{1}$ LEESU (UMR MA 102, Université Paris-Est, Agro ParisTech), 61 avenue du Général De Gaulle, 94010 Créteil Cedex, France. (E-mail: maillerr@leesu.enpc.fr; gasperi@u-pec.fr)

${ }^{2}$ LBE (UMR 0050, INRA), avenue des Etangs, 11100 Narbonne, France.

${ }^{3}$ ISA (UMR 5208, CNRS), 5 rue de la Doua, 69100 Villeurbanne, France.

${ }^{4}$ LCPP (UMR 0050, INRA), 39 bis rue de Dantzig, 75015 Paris, France.

5 SIAAP, Direction du Développement et de la Prospective, 82 avenue Kléber, 92700 Colombes, France. (E-mail: vincent.rocher@siaap.fr)

${ }^{6}$ LEESU (UMR MA 102, Université Paris-Est, Agro ParisTech), 6-8 avenue Blaise Pascal, Champs-sur-Marne, 77455 Marne-la-Vallée Cedex 2, France.

* corresponding author

\begin{abstract}
This articles aims at providing data on the contamination of different kind of sludges by a wide range of pollutants; Therefore, 70 pollutants including pharmaceuticals and hormones (PPHs), perfluorinated acids (PFAs), linear alkylbenzene sulfonate (LAS), alkylphenols (APs), phthalates (PAEs), polycyclic aromatic hydrocarbons (PAHs) and polychlorobiphenyls (PCBs) were monitored in raw, centrifuged, digested and thermally dried sludges and sludge cakes.
\end{abstract}

Very high contents of LAS (100-10,000 $\mathrm{mg} / \mathrm{kg} \mathrm{DM}$ ) compared to other compounds were found in all types of sludges followed by DEHP $(10,000-100,000 \mu \mathrm{g} / \mathrm{kg} \mathrm{DM})$ and fluoroquinolones $(1,000-$ $100,000 \mu \mathrm{g} / \mathrm{kg} \mathrm{DM})$. APs were measured at intermediary contents in Parisian sludges, lying in the 2,000-20,000 $\mu \mathrm{g} / \mathrm{kg}$ DM range. Finally, PAHs, PCBs, PAEs, PFAs and the remaining PPHs were all found at contents lower than $1,000 \mu \mathrm{g} / \mathrm{kg} \mathrm{DM}$.

For most compounds, no significant differences were found between raw sludges from Seine Aval and Seine Centre treatment plants, and between centrifuged sludge from Seine Centre and Seine Grésillons treatment plants, highlighting the homogeneity of sludge contamination in downstream Paris catchment.

For several compounds, data on their contamination are for the first time provided. For more documented compounds, a mini review of sludge contamination was performed and some difference appears as regards data reported in the literature.

Results highlighted the increase of contents through sludge treatment for LAS, APs, PAHs, DEHP and PCBs, while PPHs and PFAs are rather more eliminated than dry matter and water as their contents decrease. However, an increase of content does not automatically mean there is no removal, it simply highlights a lower removal than dry matter, and mass balances are necessary to deeply characterize the fate of compounds. This is the aim of a second article. 
In addition, the first data on centrifuged (CW) and condensed (TDW) waters from centrifugation and thermal drying were collected. Several PPHs, PFAs, LAS, PAEs, APs and PAHs were quantified in CW and TDW, displaying a transfer through the water removal. Some compounds (fluoroquinolones, LAS and PAHs) are transferred with the particulate phase (release of particles from sludge) while others are also present in the dissolved phase (PAEs, PPHs and PFAs). The concentrations observed are rather comparable to those found in wastewater.

\section{KEYWORDS}

Emerging pollutants; priority substances; sewage sludge; sludge treatment; residual water

\section{INTRODUCTION}

The presence of micropollutants in wastewater has been well demonstrated in the literature (Heberer, 2002; Loos et al., 2013; Luo et al., 2014; Verlicchi et al., 2012). A wide range of these compounds, particularly hydrophobic pollutants, are eliminated during primary and biological treatments in wastewater treatment plants (WWTP), through sorption to sewage sludges (Clara et al., 2007; Mailler et al., 2014c; Ruel et al., 2012). This results in the contamination of sewage sludges by various priority and emerging pollutants, such as alkylphenols (APs), phthalates (PAEs), polycyclic aromatic hydrocarbons (PAHs), pharmaceuticals and hormones (PPHs) or organotins (Bergé et al., 2012, 2013; Clarke and Smith, 2011; Mailler et al., 2014b).

The production of sewage sludges is estimated to be about 11 million tons of dry matter (DM) in Europe, including 1 million for France only (Kelessidis and Stasinakis, 2012). These sludges are treated and conditioned before to be land farmed, incinerated or landfilled (Fytili and Zabaniotou, 2008). In France (> 70\% of the DM mass), as well as in Europe in general (> 50\%), the main pathway for sludge management is land farming. In this context, the presence of micropollutants in sludge is of concern, especially considering the transfer from sludge to soil of some pollutants such as metals (Chipasa, 2003), organotins (Craig, 2003) or polychlorobiphenyls (PCBs) (Stevens et al., 2002). To limit contamination of the environment by micropollutants, European (EC, 1986) and national (French order of $8^{\text {th }}$ January of 1998) regulations have been established to progressively forbid sludge disposal and regulate land farming. Such regulations concern principally heavy metals, PAHs and PCBs. In particular, the Urban Wastewater Treatment Directive (EC, 1986), amended by (91/271/EEC) (EC, 1991), states maximum thresholds and maximum annual flux to land farm for metals. Moreover, present regulations are currently discussed and other compounds could possibly be added to the watch lists.

However, the studies displaying micropollutant contents in sewage sludge are still scarce compared to those for wastewater, in particular for emerging compounds such as PPHs or perfluorinated acids (PFAs). In addition, the impact of sludge treatments on micropollutant concentrations is difficult to evaluate considering that most studies do not distinguish different types of sludge from a given sludge treatment plant (STP); they just aimed at characterizing the contamination of raw and/or final treated sludge disregarding the type of sludge treatment. Finally, data about French sludge are very partial since only a dozen references are today available.

In this context, the Paris public sanitation service (SIAAP), which treats wastewater and sewage sludge from about 9 million inhabitants, and the Water Environment and Urban Systems laboratory (LEESU) have decided to assess the contamination of Parisian sewage sludges by micropollutants and their fate during sludge treatments. This project aims at i) featuring micropollutant contaminations of the different types of sludges and ii) assessing the efficiency of 4 sludge 
treatments to remove/decrease these contaminations. Therefore, raw sludge, centrifuged sludge, digested sludge, thermally dried sludge and sludge cake were studied and centrifugation, anaerobic digestion, thermal drying and cooking + press filtration were considered.

The first part of this project was mainly focused on priority pollutants and pesticides and a paper was recently published on both sludge contamination and treatments. Results shown a partial removal of alkylphenols, di(2-ethylhexyl)phthalate (DEHP), organotins and PAHs by sludge treatments, in contrary to metals and PCBs which accumulate through treatment. In addition, this work revealed that pesticides and volatile organic products were absent from Parisian sludges $(<$ LOD), or present at very low contents (<LOQ).

The second part of this project is focused on new or emerging pollutants by investigating the fate of a total of 70 compounds, including 58 new molecules, i.e. PPHs, PFAs, APs, PAEs or linear alkyl benzene sulfonates (LAS), and 12 molecules in common with the phase 1 of the project.

In addition to objectives established for phase 1, the phase 2 also aims at establishing mass balances at the scale of sludge treatments, i.e. centrifugation, digestion, thermal drying and sludge cake process, to have both a large (impact of the treatment at STPs scale) and a process engineering view (removals and transfers at processes scale). Therefore, micropollutants in condensed water from thermal drying and centrifuged water from centrifugation were investigated too, in order to

precisely identify the transfer pathways of each pollutant. Such data are among the first to be published.

Results obtained from the second part of this project are divided in two papers. The removals and transfer pathways of micropollutants are assessed in the $2^{\text {nd }}$ part of this article; this $1^{\text {st }}$ part aims at describing the contamination of the different types of Parisian sewage sludges by emerging micropollutants and comparing it to the literature. Therefore, a mini review of available data is furnished. In addition, this present article aims at i) evaluating the quality of the different types of sludges commonly encountered regarding emerging pollutants and ii) assessing their possible transfer via centrifuged and condensed water.

\section{MATERIAL AND METHODS}

\section{Sludge treatment plants (STPs) description}

The three STPs monitored are the same as described in (Mailler et al., 2014b) - Seine Aval, Seine Centre and Seine Grésillons. They are supervised by SIAAP and treat sludge produced by three WWTPs fed with wastewater from the same catchment (downstream Paris conurbation). The characteristics of each WWTP and STP are given in supporting material - Table S1, as well as the complete layout of each STP (supporting material - Table S2).

The Seine Centre plant treats $240,000 \mathrm{~m}^{3}$ of wastewater per day. Sludge produced is first centrifuged to achieve a volume reduction, resulting in a production of almost 21,000 tons DM of centrifuged sludge per year (SIAAP source). Then, sludge is incinerated producing ash and smoke, which is specifically treated to minimize odors. The Seine Aval plant receives $1,700,000 \mathrm{~m}^{3}$ of wastewater per day (biggest in Europe) and produces more than 55,000 tons DM of treated sludge per year (SIAAP source). The first sludge treatment consists in a mesophilic $\left(37^{\circ} \mathrm{C}\right)$ anaerobic digestion to transform an important part of organic matter (about 40\%) into biogas and eliminating pathogens and parasites. Digested sludge is then dewatered by thickening, thermal conditioning 
(heat exchange and cooking at $195^{\circ} \mathrm{C}$ and 20 bars) and press filtration. These successive treatments allow reducing sludge volume/mass/loads by more than a factor 10 (i.e. DM, Table 1) and producing a dewatered cake called sludge cake which is used as agricultural fertilizer. The Seine Grésillons plant treats $100,000 \mathrm{~m}^{3}$ of wastewater per day. Sludge treatment is performed by centrifugation and then thermal drying. The thermal drying process can operate at a wide range of temperature, but the facility used in this plant operates at a high temperature $\left(260^{\circ} \mathrm{C}\right)$ compared to conventional dryers (generally $105^{\circ} \mathrm{C}$ (Voulvoulis and Lester, 2006)). This allows reducing drastically the water content (Table 1) to obtain, after compacting, almost 8,000 tons DM of solid pellets per year (SIAAP source) which are stocked in big bags or silos before to be used in agriculture.

\section{Sampling strategy}

Different types of sludges have been monitored within the three studied STPs, as described in supporting material - Table S2: raw sludge (RS), centrifuged sludge (CS), digested sludge (DS), thermally dried sludge (TS) and sludge cake (SC). In addition, centrifuged (CW) and condensed water (TDW) were also analyzed to determine if a transfer occurs from sludge to water. The sampling strategy allows assessing both the contamination of final sludges and the fate of emerging micropollutants within STPs.

Sampling campaigns were performed in April-May 2013 and April 2014. Each sludge sampling point (supporting material - Table S2) was sampled seven times except the inlet and outlet of thermal drying which were sampled six times. Samples were all punctual due to technical issues, except sludge cake which is a composite sample of sludge produced within a week, respecting all the guidelines to avoid sample contamination. In addition, the sampled volume was $3 \mathrm{~L}$ for RS, CS and DS while it was $2 \mathrm{~L}$ for TS and SC. For digestion, DS was sampled 16 days after RS, to take the sludge retention time (SRT) into account. CW and TDW samples were also punctual and performed simultaneously with sludge samples in centrifugation and thermal drying.

\section{General sludge quality parameters}

The general quality of each type of sampled sludge, characterized by dry matter (DM, in $\%-1 \%=$ $10 \mathrm{~g} / \mathrm{L}$ ) and volatile matter (VM, in \% DM), is displayed in Table 1 with min - max values and mean. Both parameters are commonly used in sludge management. In addition, total suspended solids (TSS) were measured in condensed and centrifuged waters (Table 1).

Table 1. Dry matter and volatile matter content of the studied sludges

\begin{tabular}{|c|c|c|c|c|c|c|c|c|}
\hline & \multicolumn{3}{|c|}{ Digestion } & \multicolumn{2}{|c|}{ Thermal drying } & \multicolumn{2}{|c|}{ Centrifugation } & Cake \\
\hline & $\mathrm{RS}$ & DS & Removal & $\mathrm{CS}$ & $\mathrm{TS}$ & $\mathrm{RS}$ & $\mathrm{CS}$ & $\mathrm{SC}$ \\
\hline $\begin{array}{l}\mathrm{DM} \\
(\%)\end{array}$ & $\begin{array}{c}3.5-4.6 \\
3.9\end{array}$ & $\begin{array}{c}2.1-2.4 \\
2.3\end{array}$ & $\begin{array}{c}34 \%-50 \% \\
40 \%\end{array}$ & $\begin{array}{c}21.7-47.7 \\
29.7\end{array}$ & $\begin{array}{c}77.9-95.2 \\
89.9\end{array}$ & $\begin{array}{c}4.1-5.1 \\
4.7\end{array}$ & $\begin{array}{c}24.3-28.9 \\
25.9\end{array}$ & $\begin{array}{c}48.8-57.5 \\
52.1\end{array}$ \\
\hline $\begin{array}{c}\text { VM } \\
(\% \\
\text { DM) }\end{array}$ & $\begin{array}{c}71.0-80.3 \\
75.9\end{array}$ & $\begin{array}{c}57.4-60.8 \\
59.0\end{array}$ & $\begin{array}{c}46 \%-60 \% \\
54 \%\end{array}$ & $\begin{array}{c}51.0-75.9 \\
64.4\end{array}$ & $\begin{array}{c}50.3-75.8 \\
63.6\end{array}$ & $\begin{array}{c}69.2-78.5 \\
75.6\end{array}$ & $\begin{array}{c}70.7-80.3 \\
77.7\end{array}$ & $\begin{array}{c}37.3-40.0 \\
38.5\end{array}$ \\
\hline $\begin{array}{c}\text { TSS } \\
(\mathrm{mg} / \mathrm{L})\end{array}$ & & & & \multicolumn{2}{|c|}{$\begin{array}{c}8-92 \\
57\end{array}$} & \multicolumn{2}{|c|}{$\begin{array}{c}831-1,488 \\
1,220\end{array}$} & \\
\hline
\end{tabular}

Overall, removals of dry matter and volatile matter during anaerobic digestion are about $40 \%$ and $54 \%$ respectively, in good agreement with conventional anaerobic digestion removal (Mailler et al., 2014b; Moletta, 2008). This is due to the biotransformation of organic matter to methane. VM in 
sludge cake is low (38.5\% DM) compared to digested sludge highlighting a removal of organic matter during the process (thermal conditioning + press filtration, supporting material - Table S2). This is most likely due to the solubilization of a fraction of the organic matter (Neyens and Baeyens, 2003; Valo et al., 2004) during thermal conditioning $\left(195^{\circ} \mathrm{C}\right.$ and 20 bars $)$. This fraction is then removed with water during press filtration. In contrary, VM is rather constant in both thermal drying and centrifugation, highlighting that VM is whether not or similarly removed (no change in percentage) as DM during these treatments. The general quality parameters show that Seine Aval STP is the only one in the studied STPs to significantly reduce the quantity of volatile matter in sludge (not considering incineration).

Regarding CW and TDW, the TSS concentrations indicate that thermal drying performs a far more efficient separation of dry matter and water, as the concentration of TSS in TDW do not exceed 100 $\mathrm{mg} / \mathrm{l}$. TSS concentrations are 5,000 times lower than in sludge entering the process.

CW present significant higher TSS concentration (831-1,488 mg/l), about 40 times lower than RS. Considering the higher amount of particles in $\mathrm{CW}$ this could lead to transfers of pollutants from the sludge to the wastewater, as CW and TDW are reinjected in raw wastewater of the WWTPs.

\section{Pollutants and analytical procedures}

A total of 70 emerging micropollutants have been analyzed in all sampled sludges, including 58 new compounds and 12 in common with first part of the project. Table 2 gives the groups of pollutants and the main information about their respective analytical methods. Depending on the compound, three laboratories were involved in analyses: the Institute of Analytical Sciences (CNRS - Villeurbanne, France) for pharmaceuticals and perfluorinated compounds, the laboratory of Environmental Biotechnology (INRA - Narbonne, France) for hormones, LAS, alkylphenols, PAHs and PCBs, and the laboratory of the Police Prefecture of Paris (LCPP - Paris, France) for phthalates and octylphenol (OP). The complete list of monitored compounds and their limits of detection (LOD) and quantification (LOQ) are given in supporting material - Table S3.

Table 2. Pollutants and analytical methods

\begin{tabular}{|c|c|c|c|c|}
\hline Groups $^{\text {a }}$ & Total $^{\text {b }}$ & Methods $^{c}$ & Reference $^{\mathrm{d}}$ & $\mathbf{L O Q}^{\mathrm{e}}$ \\
\hline Pharmaceuticals & 18 & \multirow{2}{*}{$\begin{array}{c}\text { LG - PLE or QuEChERS - SPE - } \\
\text { (LC-MSMS) }\end{array}$} & \multirow{2}{*}{$\begin{array}{c}\text { ISA } \\
\text { (Peysson and } \\
\text { Vulliet, 2013) }\end{array}$} & $1-50$ \\
\hline Perfluorinated acids & 2 & & & 4 and 30 \\
\hline Hormones & 4 & LG - ASE - SPE - (LC-MS) & LBE & $? ?$ \\
\hline LAS & 4 & \multirow{2}{*}{ LG - ASE - (LC-FLD) } & (Patureau et al., & 40 \\
\hline PAHs & 13 & & 2012) & 20 \\
\hline $\mathrm{PCBs}$ & 20 & LG - ASE - (GC-ECD) & (Muller et al., & 8 \\
\hline Nonylphenols & 4 & LG - ASE - (LC-FLD) & 2010) & $5200-12700$ \\
\hline $\begin{array}{c}\text { OP } \\
\text { Phthalates }\end{array}$ & $\begin{array}{l}1 \\
4\end{array}$ & \multirow[t]{2}{*}{ LG - S - AC - (GC-MS) } & \multirow[t]{2}{*}{ LCPP } & \multirow[t]{2}{*}{10} \\
\hline Total & 70 & & & \\
\hline \multicolumn{5}{|c|}{$\begin{array}{l}\text { a Groups of molecules: LAS = linear alkyl benzene sulfonates; PAHs = polycyclic aromatic hydrocarbons; PCBs = } \\
\text { polychlorobiphenyls. } \\
\text { b Number of compounds per group. } \\
\text { c Methods used for extraction-purification-analysis. } \\
\text { LG = lyophilized and ground; PLE = pressurized liquid extraction; SPE = solid phase extraction; ASE = accelerated } \\
\text { solvent extraction; } \mathrm{S}=\text { sonication; AC = alumina column purification; LC = liquid chromatography; GC = gas } \\
\text { chromatography; GC-ECD = GC with pulsed flame photometric detector; } \\
\text { d Laboratories involved and bibliographic reference for the analytical method. }\end{array}$} \\
\hline
\end{tabular}


For the compounds analyzed by ISA, sludge samples are first lyophilized, grinded and sieved at 250 $\mu \mathrm{m}$. Then, for tetracyclines and fluoroquinolones, a pressurized liquid extraction is performed with a mix of acetonitrile/methanol/nitric acid (20:20:80, v:v) on a part of the sample (0.5 g). The extract $(20 \mathrm{~mL})$ is mixed with ultrapure water $(480 \mathrm{~mL})$ before to be purified by solid phase extraction (SPE) on an Autotrace ${ }^{\circledR}$ device with StrataX® cartridges, eluted with $6 \mathrm{~mL}$ of methanol. In contrary, for perfluorinated acids and the rest of pharmaceuticals, a QuEChERS extraction is performed on a part of the sample $(2 \mathrm{~g})$ with EDTA, heptane and acetate buffer. Then, a purification step is performed by SPE. Both parts of the sample are then analyzed by LC-MSMS.

For the compounds analyzed by LBE, sludge samples are also lyophilized and grinded, before to be centrifuged. The sample is extracted by accelerated solvent extraction with hexane/acetone (50:50, $\mathrm{v}: \mathrm{v})$ for alkylphenols, PAHs and PCBs, methanol for LAS and methanol/acetone (50:50, v:v) for hormones. The extract is purified by SPE for hormones analysis. Finally, the three fractions of the sample are analyzed by LC-FLD for LAS, alkylphenols and PAHs, LC-MS for hormones and GCECD for PCBs.

For OP and phthalates, samples were frozen during 72 hours at a temperature of $-18^{\circ} \mathrm{C}$. After lyophylization, about $1 \mathrm{~g}$ of sample was extracted by sonication in $20 \mathrm{~mL}$ of mixture of methanol/dichloromethane $(10: 90, \mathrm{v}: \mathrm{v})$. This step was repeated twice to ensure complete extraction of the compounds. Both extracts were then purified on an alumina column $(1 \mathrm{~g})$, previously conditioned with $6 \mathrm{~mL}$ of dichloromethane. The extracts were then concentrated under a stream of nitrogen to a final volume of $1 \mathrm{~mL}$. The concentrate was taken up in $1 \mathrm{~mL}$ of mixture of methanol and dichloromethane containing the internal standards. All chemicals and solvents were pesticide residue grade. OP and phthalates were analyzed by GC-MS (simple Quad, Agilent Technologies).

More information about the analytical methods used in this article are given in (Patureau et al., 2012) for LAS, nonylphenols, PCBs and PAHs, (Muller et al., 2010) for hormones, (Peysson and Vulliet, 2013) for pharmaceuticals and PFAs.

\section{RESULTS AND DISCUSSION}

\section{Pharmaceuticals and hormones (PPHs)}

PPHs are compounds that are not expected to be sorbed to sewage sludge a priori, considering their hydrophilic nature. However, most of PPHs monitored were detected in each type of sludge. The PPHs contents for each type of sludge considered are provided in Figure 1. Statistical data such as Fischer, Student and Mann-Whitney tests, to compare homogeneity of RS and CS from STP to STP, are provided in supporting material - Table S6. Occurrences of the compounds are also furnished in supporting materials - Table S4.

In raw sludges (Figure 1) and based on all RS samples (14 samples), all PPHs monitored were detected. Moreover, acetaminophen, carbamazepine, ciprofloxacin, domperidone, escitalopram, lidocaine, norfloxacin, ofloxacin, propranolol, tramadol and verapamil have a frequency of detection higher than 50\%, while the remaining compounds are detected scarcely (occurrence < $50 \%$ ). Fluoroquinolones (ofloxacin, ciprofloxacin and norfloxacin) are predominant in sludge with high contents (> 3,000 $\mu \mathrm{g} / \mathrm{kg} \mathrm{DM})$ while other PPHs lay in the $10-1000 \mu \mathrm{g} / \mathrm{kg} \mathrm{DM}$ range. For these 
latter compounds, ciprofloxacin has the highest content, with a median value of $10,285 \mu \mathrm{g} / \mathrm{kg} \mathrm{DM}$. Sulfamethoxazole, acetaminophen or lidocaine are found in median around $100 \mu \mathrm{g} / \mathrm{kg} \mathrm{DM}$.

In addition, a statistical analysis performed on RS $(\mathrm{N}=14)$ demonstrated that PPHs contents are not significantly different ( $\mathrm{p}$-value $>0.05$ - confidence level of 95\%) between Seine Aval and Seine Centre (Fischer, Student and Mann-Whitney tests, see supporting material - Table S6). This indicates that sewage sludge is quite homogenous in Paris, despite different wastewater treatment processes. This is consistent as the different WWTPs studied treat wastewater from the same catchment. A similar trend is observed between CS from Seine Centre and Seine Grésillons. Finally, DEHP, APs, LAS and PAHs also have comparable contents in RS from Seine Aval and Seine Centre and in CS from Seine Centre and Seine Grésillons (supporting material - Table S6).

In treated sludges (CS, DS, TS and SC), the number of compounds detected and the occurrence are lower than in RS. The fluoroquinolones $(n=3)$ and carbamazepine are the only compounds to be still frequently detected in all treated sludges.

In TS and SC, which are both final sludges that are actually used as agricultural amendment, most compounds are measured at lower contents than in RS. For instance, acetaminophen and ciprofloxacin were respectively measured at a median RS content of 90.9 and $12,858 \mu \mathrm{g} / \mathrm{kg} \mathrm{DM}$ against 47.6 and $6,077 \mu \mathrm{g} / \mathrm{kg} \mathrm{DM}$ in TS, and 65.4 and $7,438 \mu \mathrm{g} / \mathrm{kg}$ DM in SC. This highlights the positive impact of the STP on micropollutant contamination of the sludge, although they were not designed for that.

However, some compounds have similar or higher contents in TS or SC compared to RS. For instance, carbamazepine, domperidone, escitalopram, ofloxacin and propranolol have similar contents in TS and RS. Ofloxacin has also a comparable content in SC while loratadine is much more concentrated in cake $(1,360 \mu \mathrm{g} / \mathrm{kg} \mathrm{DM}-$ median) than in RS $(38 \mu \mathrm{g} / \mathrm{kg} \mathrm{DM})$. These recalcitrant compounds are whether similarly or less removed than dry matter during the sludge treatment process, leading sometimes to content increase, even if the mass flux has actually decreased. The part 2 of this article will focus more particularly on the mass balance and transfer during treatment.

In DS, acetaminophen, carbamazepine, miconazole and fluoroquinolones have similar or higher contents than RS, resulting from a low biodegradability (no biodegradation or weaker than the dry matter). The remaining compounds are not or scarcely $(<3$ times $)$ detected, displaying a notable impact of this process on sludge contamination (content decrease).

In CS, no transformation of the compounds can theoretically occur as this process consists in a simple physical separation of sludge and water. However, most PPHs $(n=10)$ have lower contents in CS comparatively to RS, indicating a removal. In contrary, azithromycin, domperidone, glybencyclamide, loratadine, miconazole, and fluoroquinolones have similar or higher contents in CS.

Finally, comparing DS and SC allows having an idea of the impact of cooking and press filtration on sludge contamination. A reduction of contamination is observed for several compounds, i.e. acetaminophen, carbamazepine, miconazole and the three fluoroquinolones. This reduction should be due to solubilization and removal of water (Neyens and Baeyens, 2003; Valo et al., 2004). Moreover, acetaminophen and carbamazepine are also removed during centrifugation. In contrary, the other pharmaceuticals are rather accumulated as their contents are higher after cooking and 
press filtration.

The variability of contents is high for most pharmaceuticals in RS with coefficients of variability (CV) between $50 \%$ and $150 \%$ (based on 14 RS samples), as a probable result of the variability of concentrations in wastewater. In treated sludge, the variability remains high, especially in CS (33$200 \%$ ) and TS (25-170\%), except for digestion which seems to have a buffer effect (6-100\%).

Regarding the literature (supporting material - Table S3), several works have displayed their propensity to be present in the particulate fraction thanks to adsorption mechanisms (Carballa et al., 2004; Giger et al., 2003; Lindberg et al., 2005a). Some pharmaceuticals were monitored in sewage sludge in different countries and the data available are rather large. Some compounds are well documented such as acetaminophen, azithromycin, carbamazepine, fluoroquinolones, propranolol or sulfamethoxazole but not for all types of sludge and without a process engineering point of view. Azithromycin, when detected, was found at lower contents in RS than former studies (Clarke and Smith, 2011; Göbel et al., 2005). In contrary, ciprofloxacin (Golet et al., 2003; Li et al., 2013), ofloxacin (Jones et al., 2014), carbamazepine (Nieto et al., 2010), sulfamethoxazole (Li et al., 2013; Nieto et al., 2010) and propranolol (Jones et al., 2014; Nieto et al., 2010) are rather more concentrated in RS from this study, because of a higher contamination of wastewater and/or more efficient treatments in WWTP resulting in a greater sorption. In treated sludges, data from the literature are in accordance with what is observed in Paris for acetaminophen, azithromycin, carbamazepine, propranolol and sulfamethoxazole (Clarke and Smith, 2011; Harrison et al., 2006; Narumiya et al., 2013; Peysson and Vulliet, 2013; Radjenović et al., 2009; Subedi et al., 2014), but fluoroquinolones are more concentrated than in former studies (Golet et al., 2003; Jia et al., 2012; Lindberg et al., 2005b).

In contrary, no or very few data were found for domperidone, escitalopram, glybencyclamide, ivermectine, lidocaine, loratadine, miconazole, tramadol and verapamil, whatever the type of sludge. 


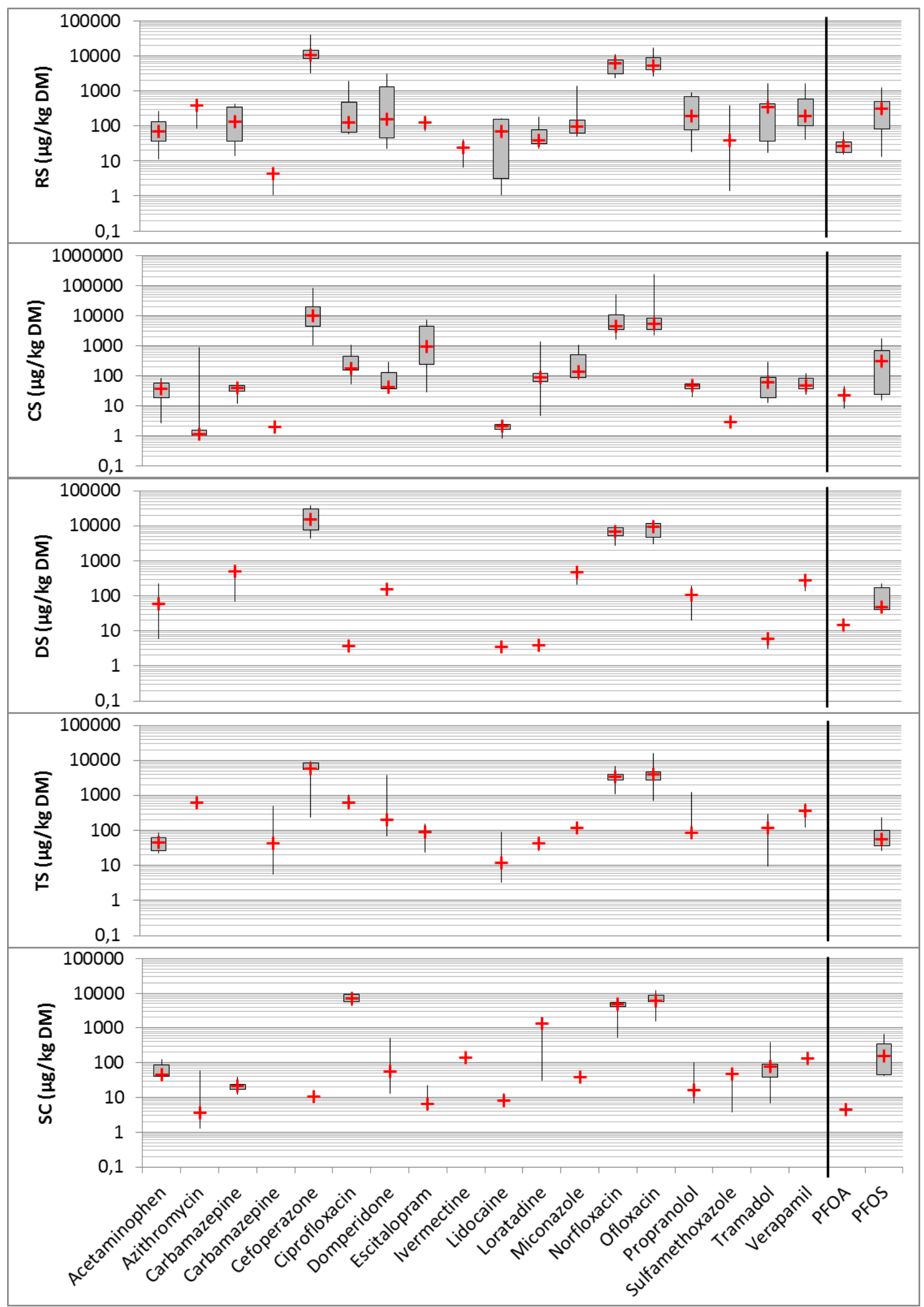

Figure 1. Pharmaceuticals and PFAs contents in Parisian sewage sludges 


\section{2. $\quad$ Perfluorinated acids (PFAs)}

PFAs are emerging pollutants with a growing interest. They are classified as priority substances since 2013 (EC, 2013). Similarly to fluoroquinolones, PFOS was always detected in all sludges contrary to PFOA with a lower occurrence $(<50 \%)$. PFOA was never detected in TS, and only 2 times in SC and DS. Their sludge contents are in the range of those from pharmaceuticals (Figure 1). In RS, the median content of PFOA and PFOS are respectively 26 and $316 \mu \mathrm{g} / \mathrm{kg} \mathrm{DM}$. For both compounds, the contents measured in the different treated sludges were lower, indicating a partial removal during treatments, even during centrifugation. Thus, PFOS was measured at a median content of $293 \mu \mathrm{g} / \mathrm{kg}$ DM in CS, $49 \mu \mathrm{g} / \mathrm{kg} \mathrm{DM}$ in DS, $55 \mu \mathrm{g} / \mathrm{kg} \mathrm{DM}$ in TS and $157 \mu \mathrm{g} / \mathrm{kg}$ DM in SC.

Similarly to pharmaceuticals, the variability of content is relatively high for perfluorinated compounds with CV between 60 and $120 \%$. The variability for these compounds is similar in all kind of sludges.

PFOA contents found in the literature are similar to those observed in Paris sludge (Bossi et al., 2008; Loganathan et al., 2007; Stasinakis et al., 2013). Contrariwise, PFOS seems to be notably more concentrated in Parisian sludges, with contents in the literature lower than $100 \mu \mathrm{g} / \mathrm{kg} \mathrm{DM}$ (Arvaniti et al., 2012; Schultz et al., 2006; Sinclair and Kannan, 2006). A higher contamination of raw wastewater leading to a higher sorption of PFAs on sludge could explain this difference.

\section{PAHs}

PAHs are cited in French sludge regulations (order of $8^{\text {th }}$ January of 1998). In this text, threshold values are stated for fluoranthene $(5,000 \mu \mathrm{g} / \mathrm{kg} \mathrm{DM})$, benzo[b]fluoranthene $(2,500 \mu \mathrm{g} / \mathrm{kg} \mathrm{DM})$ and benzo[a]pyrene $(2,000 \mu \mathrm{g} / \mathrm{kg} \mathrm{DM})$, limiting the use of contaminated sludge for agricultural amendment.

Regarding the Parisian sewage sludge (Figure 2; supporting material - Table S4), the 13 monitored PAHs were detected in all analyzed samples. The PAHs pattern is similar in the different sludges (Figure 2), even if some differences of contents can be observed from sludge to sludge. Thus, anthracene and dibenzo[ $a]$ anthracene have significantly lower contents than the other PAHs, always lower than $100 \mu \mathrm{g} / \mathrm{kg}$ DM. In contrary, phenanthrene, fluoranthene and pyrene are always the most concentrated PAHs in sludge, with contents higher than $100 \mu \mathrm{g} / \mathrm{kg}$ DM. PAHs are rather more concentrated in treated sludges, especially SC, as already observed in a former study (Mailler et al., 2014b). Concerning TS and SC, managed through land farming, the three regulated compounds were never measured above the threshold values. Indeed, these molecules were always measured below $800 \mu \mathrm{g} / \mathrm{kg} \mathrm{DM}$, whatever the sludge.

The variability of content observed for PAHs is moderate $(50 \%<\mathrm{CV}<100 \%)$ in $\mathrm{RS}$ except for dibenzo[ah] anthracene for which it is high $(\mathrm{CV}=114 \%)$. Sludge treatments reduce this variability and the coefficients of variability of all PAHs are below 50\% in DS, TS and SC.

The RS contents observed in Paris are lower than in China (Cai et al., 2007; Zeng et al., 2010), Korea (Ju et al., 2009) and UK (Jones et al., 2014) for all PAHs. Overall, the contents found in Parisian treated sludge in this study (sampling in 2013-2014) are very close from those found in 2011 (Mailler et al., 2014b). Furthermore, another recent French study measured comparable contents in various French STPs (Besnault et al., 2015 (submitted)). This suggests that PAHs contamination of sewage sludge is rather homogenous in France. The results are also comparable to 
those from (Aparicio et al., 2009) but higher contents were found in digested sludge from UK (Stevens et al., 2002).

\section{Phthalates (PAEs)}

PAEs were only monitored in 2014 ( $n=3-7$ campaigns, depending on the STP). 4 compounds were monitored including the di(2-ethylhexyl) phthalate (DEHP), benzylbutyl phthalate (BBP), di-nbutyl phthalate (DnBP) and diethyl phthalate (DEP). The 4 compounds were found in all samples from RS, CS, DS and TS but BBP was not detected in SC while DnBP and DEP were only detected once in this sludge.

DEHP is present at much higher contents in Parisian sludge than the three other compounds (Figure 2). Thus, this molecule was measured at a median content of $41,500 \mu \mathrm{g} / \mathrm{kg} \mathrm{DM}$ in RS, $70,600 \mu \mathrm{g} / \mathrm{kg} \mathrm{DM}$ in CS, 58,100 $\mu \mathrm{g} / \mathrm{kg} \mathrm{DM}$ in DS, 90,200 $\mu \mathrm{g} / \mathrm{kg}$ DM in TS and $68,300 \mu \mathrm{g} / \mathrm{kg}$ DM in SC. BBP, DEP and DnBP are found in the same range as PAHs, with median content of 44.9$144.6 \mu \mathrm{g} / \mathrm{kg}$ DM for DEP, 351.9-1,141.0 $\mu \mathrm{g} / \mathrm{kg}$ DM for BBP and 109.3-290.6 $\mu \mathrm{g} / \mathrm{kg}$ DM for DnBP. The contents in DS and SC are always lower or similar than in RS for BBP, DEP and DnBP, highlighting a removal close or higher than dry matter. In contrary, DEHP accumulates in sludge throughout the treatment process, resulting in an increase of the content.

For PAEs, RS and CS are the only sludge with enough samples $(n=6-7)$ to estimate the variability of content. The latter is low $(\mathrm{CV}<50 \%)$ in both sludges, except for BBP which is more variable (55$80 \%)$.

In the literature, most studies found these compounds at comparable contents, especially in European countries (Bergé et al., 2013; Clara et al., 2010; Clarke and Smith, 2011; Gibson et al., 2005). However, Chinese (Cai et al., 2007) - factor 10 for DEP and DnBP - and Spanish (Abad et al., 2005; Aparicio et al., 2009) - factor 3 for DEHP - sludges appear more contaminated, just like PAHs. 


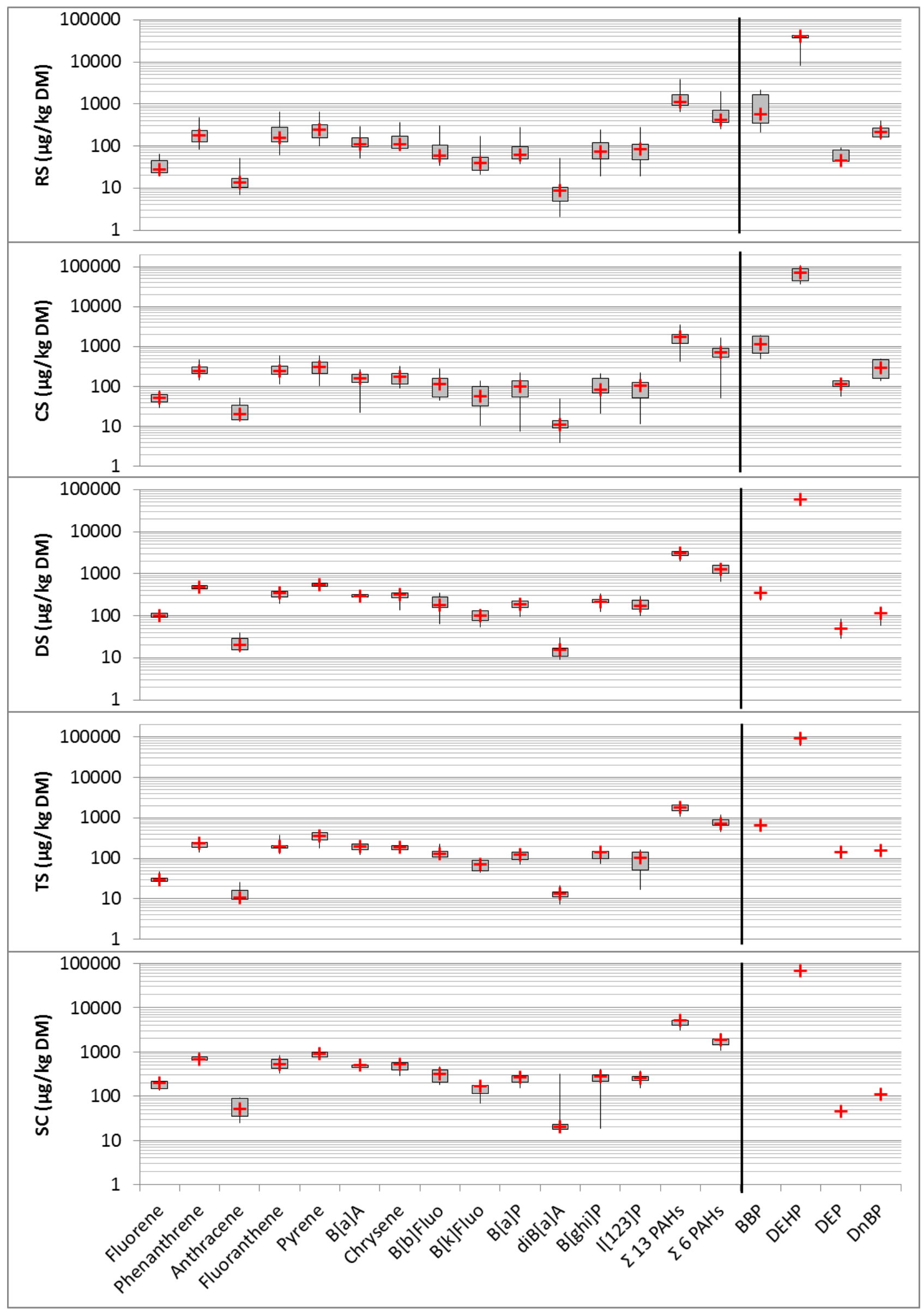

Figure 2. PAHs and PAEs contents in Parisian sewage sludges 


\section{Alkylphenols (APs)}

For APs, nonylphenols (NP), octylphenol (OP), nonylphenol monoethoxylate (NP1EO) and diethoxylate (NP2EO), as well as the sum of analyzed nonylphenols ethoxylates ( $\Sigma$ NPEOs), were monitored. OP, NP and NP1EO were detected in every sludge sample, contrary to NP2EO with an occurrence below $50 \%$ in CS, TS and SC.

In RS, NP, NP1EO and NP2EO had a comparable median content, respectively 1,380, 1,720 and $940 \mu \mathrm{g} / \mathrm{kg}$ DM (Figure 3). While the repartition and the contents are similar to RS in CS and TS, this is slightly different for DS and SC. In DS and SC, the three compounds have a higher median content $(4,520,3,380$ and $1,300 \mu \mathrm{g} / \mathrm{kg} \mathrm{DM})$. This increase of contents results from dry matter and water removals. OP has a comparable content whatever the sludge, with a median content varying between 190 and $609 \mu \mathrm{g} / \mathrm{kg}$ DM depending on the sludge.

The variability of content observed is from relatively low to moderate for these compounds, with CV of $20-60 \%$. This is surprising for DS taking their biodegradability into account and the fact that NP1EO and NP2EO can be degraded in NP during such treatment (Ejlertsson et al., 1998; Lu et al., 2008). Moreover, very variable removals were observed previously on the same facilities (Mailler et al., 2014b), inducing a much higher variability of content in DS, SC and TS.

NP and nonylphenols ethoxylates in sewage sludge have been well studied in the literature, particularly in treated sludge (supporting material - Table S5). Contents available are rather variable, even for one type of sludge, and the contamination of Parisian sludge is in the lower range. In particular, several studies measured these compounds at much higher contents than what is observed in this study (Aparicio et al., 2009; Ghanem et al., 2007; González et al., 2010; Samaras et al., 2013), while others at comparable levels (Jones et al., 2014; Mailler et al., 2014b; Nie et al., 2009). For OP, no comparison was found in the literature.

\section{LAS}

LAS analyses include analyses of $\mathrm{C} 10, \mathrm{C} 11, \mathrm{C} 12$ and $\mathrm{C} 13$ congeners, as well as the sum of LAS content. LAS, whatever the chain length (C10-C13), were always detected in all types of sludge (Figure 3). These compounds are measured at very high contents in sludge compared to all the other emerging micropollutants, i.e. about $100-10,000 \mathrm{mg} / \mathrm{kg} \mathrm{DM}$.

In RS, C10 is always significantly less concentrated than the others with a median content of 193 $\mathrm{mg} / \mathrm{kg}$ DM, while C11, C12 and C13 have close median contents of respectively 1,171, 1,484 and $982 \mathrm{mg} / \mathrm{kg}$ DM. Similarly to PAHs, the LAS pattern doesn't change with the sludge treatment; the LAS proportions are stable, indicating that the 4 compounds are similarly impacted by the treatments. The pattern observed is in accordance with most of former studies (Aparicio et al., 2009; Carballa et al., 2007; Muller et al., 2007) with a predominance of C10 in comparison to C11, C12 and C13. Moreover, LAS contents are rather similar or higher in treated sludge compared to RS, indicating that they are not notably eliminated by the processes or at least less than the dry matter. For instance, the median $\Sigma$ LAS content varies from $4,053 \mathrm{mg} / \mathrm{kg}$ DM in RS to $6,224 \mathrm{mg} / \mathrm{kg}$ DM in CS, $5,161 \mathrm{mg} / \mathrm{kg}$ DM in DS, 7,400 mg/kg DM in TS and $8,821 \mathrm{mg} / \mathrm{kg}$ DM in SC.

The variability of contents is low for this group of compounds, with CV between 25 and $35 \%$ in RS, $25-50 \%$ in CS, $20-25 \%$ in DS and 10-40\% in TS. In SC, this variability is even lower $(<15 \%)$.

LAS are studied for a couple of decades in sewage sludges and the literature available is quite large 
(supporting material - Table S5). About 20 references were found. In addition, the contents observed are rather variable from study to study, from a mean value of total LAS of $10.7 \mathrm{mg} / \mathrm{kg} \mathrm{DM}$ in China (Zeng et al., 2012) to more than 10,000 mg/kg DM in UK (Holt and Bernstein, 1992) and Greece (Pakou et al., 2009). However, most studies provided data that are consistent with what is observed in Paris. Furthermore, no data were found for centrifuged and thermally dried sludge for this group of compounds.

\section{7. $\quad$ PCBs}

PCBs ( $n=20)$ were only monitored in 2013 (N=3-4 campaigns). Similarly to PAHs, French regulation stated a threshold value $(800 \mu \mathrm{g} / \mathrm{kg} \mathrm{DM})$ for the sum of 7 PCBs (PCB 28, 52, 101, 118, 138, 153 and 180).

Contents measured in RS for PCBs (supporting material - Table S4) lie in the 10-2,000 $\mu \mathrm{g} / \mathrm{kg} \mathrm{DM}$ range for individual PCBs. This range is similar to the one for PPHs, PFAs and PAHs. The 7 PCBs from the French regulation are those with the highest contents, leading to a median value of the sum of $518 \mu \mathrm{g} / \mathrm{kg}$ DM, what is below the French threshold value. They represent $60-75 \%$ of the total PCBs content in RS. In addition, PCB 101 is the only congener with a median content higher than $100 \mu \mathrm{g} / \mathrm{kg} \mathrm{DM}(106 \mu \mathrm{g} / \mathrm{kg} \mathrm{DM})$, while other congeners 18, 33, 105, 128, 170, 187, 194, 195, 199, 206 and 209 were measured at a median content below $20 \mu \mathrm{g} / \mathrm{kg} \mathrm{DM}$.

An increase of PCBs content in sludge is observed during sludge treatments, with higher contents observed in DS, CS and SC than in RS. For instance, PCB 101 median contents in CS, DS and SC are respectively 132, 203 and $368 \mu \mathrm{g} / \mathrm{kg} \mathrm{DM}$. SC is the sludge with the highest PCB contents resulting from the reduction of the mass of sludge in digestion and cooking followed by press filtration. This has already been observed within the same STPs (Mailler et al., 2014b). Thus, the $\Sigma$ 7 PCBs content reaches a median value of $2,503 \mu \mathrm{g} / \mathrm{kg} \mathrm{DM}$ in SC, what is significantly higher than the threshold value, and the total PCBs content reaches $3,368 \mu \mathrm{g} / \mathrm{kg}$ DM. In contrary, a decrease of content is observed for all PCBs after thermal drying. This phenomenon is stronger for the lighter congeners. This results in lower PCBs contents in TS than in the other sludges, in particular RS. In this type of sludge, the $\Sigma 7$ PCBs and $\Sigma 20$ PCBs median contents are respectively 304 and 523 $\mu \mathrm{g} / \mathrm{kg} \mathrm{DM}$.

Similarly to APs, PCBs are more concentrated in Parisian sludge than in the other studies available (Abad et al., 2005; Gibson et al., 2005; Ju et al., 2009; Muller et al., 2007; Stevens et al., 2002). In contrary, (Blanchard et al., 2004) measured the $\Sigma 7$ PCBs in French treated sludge between 120 and $1,930 \mu \mathrm{g} / \mathrm{kg}$ DM. This could suggest a decrease of sludge contamination by these compounds in ten years, as it was previously observed in France for metals (Mailler et al., 2014a) or in Sweden for some polybromodiphenylethers and norfloxacin (Olofsson et al., 2012). 


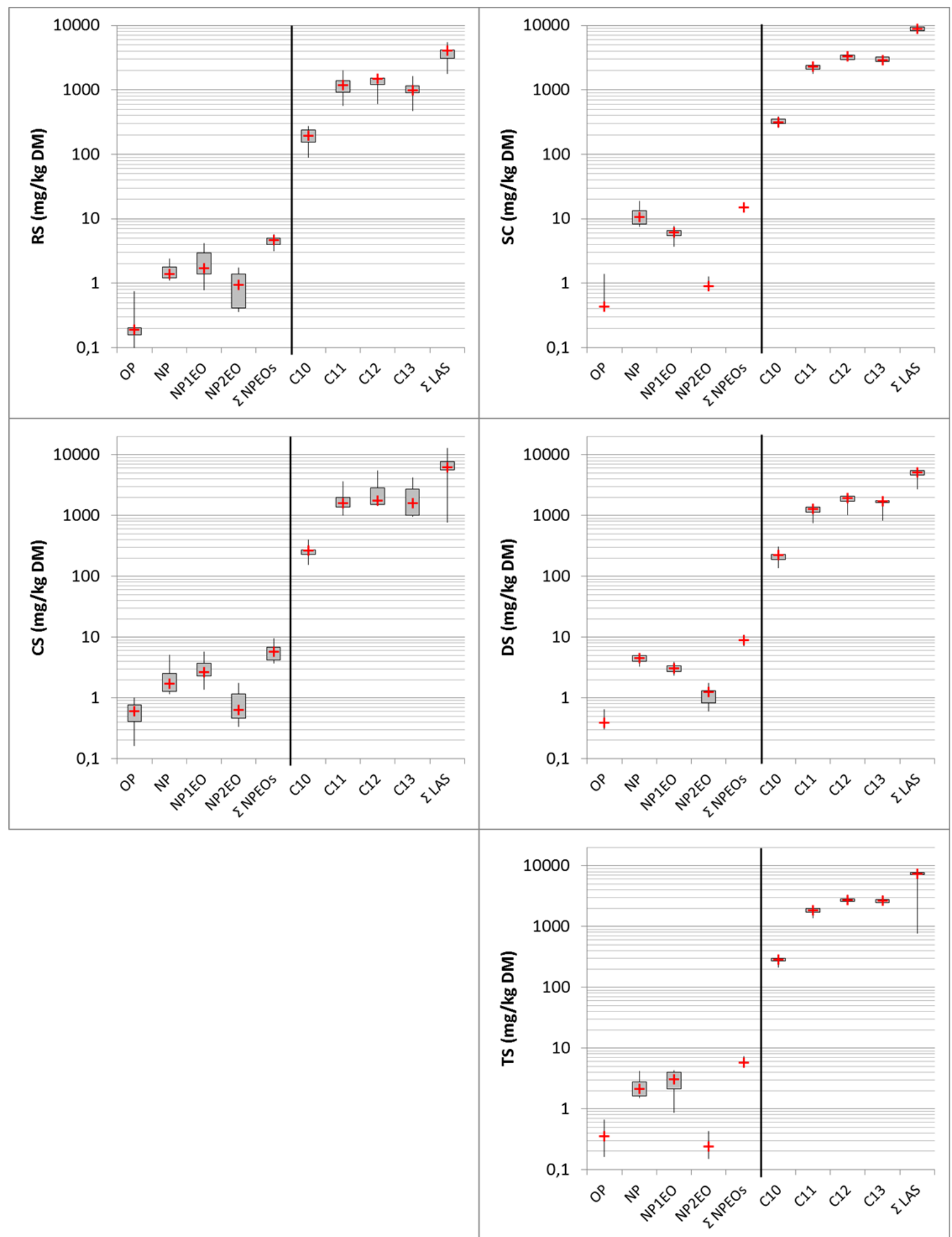

Figure 3. APs and LAS contents in Parisian sewage sludges 


\section{Micropollutant concentrations in CW and TDW}

All micropollutants monitored in sludges, except PCBs, were also monitored in 2014 in the centrifuged (CW) and condensed (TDW) waters from centrifugation and thermal drying to identify possible transfer pathways.

Most pollutants (36 on the 50 monitored) were detected in CW except several PPHs, including carbamazepine, miconazole or sulfamethoxazole. LAS, APs, PAHs and PAEs were detected in all samples. Similarly to sludge, LAS are measured at very high concentrations, lying in the 50,000250,000 ng/L range. DEHP, DEP and DnBP concentrations are also high (1,000-12,500 ng/L), while BBP, APs and PAHs are quantified at notably lower concentrations (1-1,000 ng/L).

For PPHs, acetaminophen, azithromycin, lidocaine, propranolol and tramadol were systematically detected in CW (Table 3). In addition, domperidone, fluoroquinolones and verapamil, as well as PFAs, were detected at least ones. These molecules were quantified at relatively low concentrations (5-2,300 $\mathrm{ng} / \mathrm{L})$, in the same range as APs and PAHs, except fluoroquinolones and azithromycin which are measured between 2,000 and $6,000 \mathrm{ng} / \mathrm{L}$.

Regarding the partitioning of compounds in $\mathrm{CW}$, three cases are encountered. First, acetaminophen, lidocaine and tramadol were only detected in the dissolved phase. It could be assumed that these compounds were initially present in the dissolved phase in RS and not sorbed to dry matter. This is consistent considering their hydrophilic properties $\left(\log \mathrm{K}_{\mathrm{OW}}<2.5\right)$. The contamination of $\mathrm{CW}$ for them could be hence due to their high affinity for dissolved phase.

Then, LAS, PAHs, APs, fluoroquinolones and verapamil were only detected in the particulate phase, what is consistent as they are hydrophobic $\left(\log \mathrm{K}_{\mathrm{OW}}>4\right)$ or have a great affinity for sorption on particles (Byrns, 2001; Gasperi et al., 2010; Golet et al., 2003; Zhou et al., 2013). For these compounds, the contamination of $\mathrm{CW}$ is due to the fraction of TSS lost during centrifugation.

Finally, the remaining detected compounds were found in both dissolved and particulate phase. Thus, for PFA, azithromycin, domperidone, propranolol, OP and PAEs, the contamination of CW is due to both presence in water and TSS lost.

In TDW, regarding the low concentration of TSS (Table 1), only dissolved concentrations were assessed. PAHs, LAS and most PPHs were not quantified in dissolved phase of TDW. However azithromycin (350-3000 ng/L), lidocaine (64-178 ng/L), tramadol (184-2315 ng/L) and verapamil $(<\mathrm{LOQ}-301 \mathrm{ng} / \mathrm{L})$ were detected in TDW samples. In addition, NP (3400-5350 ng/L), OP (732$2133 \mathrm{ng} / \mathrm{L})$ and PAEs (67-30119 ng/L) were also detected in all TDW samples.

The results from TDW confirm that a very efficient separation of particles and water (thermal drying), doesn't lead to a complete prevention of the micropollutant transfers with the residual waters, as a fraction of several pollutants is transferred with the dissolved phase.

These results about micropollutants in residual waters from sludge treatment are the first published and are required to understand well the micropollutant transfers in STPs. A deeper analysis of the removal pathways (dissolved and/or particulate fraction) and mass balances will be performed in a second article. 
Table 3. Concentrations measured in centrifuged (CW) and condensed (TDW) water in 2014 campaigns

\begin{tabular}{|c|c|c|c|c|c|c|}
\hline \multirow{2}{*}{ Pollutant } & CW 1 & CW 2 & CW 3 & TDW 1 & TDW 2 & TDW 3 \\
\hline & \multicolumn{3}{|c|}{ Total concentration $(\mathrm{ng} / \mathrm{L})$} & \multicolumn{3}{|c|}{ Dissolved concentration $(n g / L)$} \\
\hline Acetaminophen & 233 & 274 & 424 & $<\mathrm{LOQ}$ & $<$ LOQ & $<\mathrm{LOQ}$ \\
\hline Azithromycin & 5529 & 4733 & 359 & 350 & 2949 & 408 \\
\hline Carbamazepine & $<\mathrm{LOQ}$ & $<\mathrm{LOQ}$ & $<\mathrm{LOQ}$ & $<\mathrm{LOQ}$ & $<\mathrm{LOQ}$ & $<\mathrm{LOQ}$ \\
\hline Cefoperazone & $<\mathrm{LOQ}$ & $<\mathrm{LOQ}$ & $<\mathrm{LOQ}$ & $<\mathrm{LOQ}$ & $<\mathrm{LOQ}$ & $<\mathrm{LOQ}$ \\
\hline Ciprofloxacin & $<\mathrm{LOQ}$ & $<\mathrm{LOQ}$ & $\underline{2,283}$ & $<\mathrm{LOQ}$ & $<\mathrm{LOQ}$ & $<\mathrm{LOQ}$ \\
\hline Domperidone & $<\mathrm{LOQ}$ & 88 & 178 & $<\mathrm{LOQ}$ & $<\mathrm{LOQ}$ & $<\mathrm{LOQ}$ \\
\hline Escitalopram & $<\mathrm{LOQ}$ & $<\mathrm{LOQ}$ & $<\mathrm{LOQ}$ & $<\mathrm{LOQ}$ & $<\mathrm{LOQ}$ & $<\mathrm{LOQ}$ \\
\hline Glybencyclamide & $<\mathrm{LOQ}$ & $<\mathrm{LOQ}$ & $<\mathrm{LOQ}$ & $<\mathrm{LOQ}$ & $<\mathrm{LOQ}$ & $<\mathrm{LOQ}$ \\
\hline Ivermectine & $<\mathrm{LOQ}$ & $<\mathrm{LOQ}$ & $<\mathrm{LOQ}$ & $<\mathrm{LOQ}$ & $<\mathrm{LOQ}$ & $<\mathrm{LOQ}$ \\
\hline Lidocaine & 278 & 185 & 94 & 82 & 178 & 64 \\
\hline Loratadine & $<\mathrm{LOQ}$ & $<\mathrm{LOQ}$ & $<\mathrm{LOQ}$ & $<\mathrm{LOQ}$ & $<\mathrm{LOQ}$ & $<\mathrm{LOQ}$ \\
\hline Miconazole & $<\mathrm{LOQ}$ & $<\mathrm{LOQ}$ & $<\mathrm{LOQ}$ & $<\mathrm{LOQ}$ & $<\mathrm{LOQ}$ & $<\mathrm{LOQ}$ \\
\hline Norfloxacin & $<\mathrm{LOQ}$ & $<\mathrm{LOQ}$ & $\underline{2,066}$ & $<\mathrm{LOQ}$ & $<\mathrm{LOQ}$ & $<\mathrm{LOQ}$ \\
\hline Ofloxacin & $<\mathrm{LOQ}$ & $<\mathrm{LOQ}$ & 2029 & $<\mathrm{LOQ}$ & $<\mathrm{LOQ}$ & $<\mathrm{LOQ}$ \\
\hline Propranolol & 407 & 522 & $\underline{513}$ & $<\mathrm{LOQ}$ & $<\mathrm{LOQ}$ & $<\mathrm{LOQ}$ \\
\hline Sulfamethoxazole & $<\mathrm{LOQ}$ & $<\mathrm{LOQ}$ & $<\overline{\mathrm{LOQ}}$ & $<\mathrm{LOQ}$ & $<\mathrm{LOQ}$ & $<\mathrm{LOQ}$ \\
\hline Tramadol & 942 & 1163 & 587 & 515 & 2315 & 184 \\
\hline Verapamil & $<\mathrm{LOQ}$ & $\underline{114}$ & $<\mathrm{LOQ}$ & $<\mathrm{LOQ}$ & 301 & 283 \\
\hline PFOA & 8 & 5 & $<\mathrm{LOQ}$ & 5 & 11 & $<\mathrm{LOQ}$ \\
\hline PFOS & 26 & $<\mathrm{LOQ}$ & 24 & 29 & 52 & $<\mathrm{LOQ}$ \\
\hline OP & 278 & $<\mathrm{LOQ}$ & 91 & 2133 & 1314 & 732 \\
\hline NP & $\underline{610}$ & 940 & $\underline{590}$ & 3400 & 3800 & 5350 \\
\hline NP1EO & $\overline{140}$ & $\underline{90}$ & $\overline{220}$ & - & - & - \\
\hline NP2EO & $\underline{80}$ & $\underline{80}$ & $\underline{230}$ & - & - & - \\
\hline BBP & 396 & 302 & 299 & 186 & 288 & 67 \\
\hline DEHP & 2939 & 2816 & 12493 & 30119 & 21630 & 4080 \\
\hline DEP & 1404 & 2101 & 1097 & 1165 & 1676 & 445 \\
\hline DnBP & 3229 & 3172 & & 2560 & 2520 & 4932 \\
\hline $\mathrm{C} 10$ & 69609 & 70660 & 65861 & $<\mathrm{LOQ}$ & $<\mathrm{LOQ}$ & $<\mathrm{LOQ}$ \\
\hline $\mathrm{C} 11$ & $\overline{781899}$ & 203487 & $\overline{190669}$ & $<\mathrm{LOQ}$ & $<\mathrm{LOQ}$ & $<\mathrm{LOQ}$ \\
\hline $\mathrm{C} 12$ & 124308 & 182687 & $\underline{171976}$ & $<\mathrm{LOQ}$ & $<\mathrm{LOQ}$ & $<\mathrm{LOQ}$ \\
\hline C13 & 64088 & 113839 & 64789 & $<\mathrm{LOQ}$ & $<\mathrm{LOQ}$ & $<\mathrm{LOQ}$ \\
\hline$\Sigma$ LAS & $\underline{1039904}$ & $\underline{570664}$ & $\underline{493294}$ & - & - & - \\
\hline Fluorene & 10 & 7 & 11 & $<\mathrm{LOQ}$ & $<\mathrm{LOQ}$ & $<\mathrm{LOQ}$ \\
\hline Phenanthrene & $\underline{45}$ & $\underline{38}$ & $\underline{37}$ & $<\mathrm{LOQ}$ & $<\mathrm{LOQ}$ & $<\mathrm{LOQ}$ \\
\hline Anthracene & $\overline{0,6}$ & $\overline{0,7}$ & $\overline{7}$ & $<\mathrm{LOQ}$ & $<\mathrm{LOQ}$ & $<\mathrm{LOQ}$ \\
\hline Fluoranthene & $\overline{117}$ & $\underline{47}$ & 607 & $<\mathrm{LOQ}$ & $<\mathrm{LOQ}$ & $<\mathrm{LOQ}$ \\
\hline Pyrene & $\underline{42}$ & $\underline{24}$ & $\underline{28}$ & $<\mathrm{LOQ}$ & $<\mathrm{LOQ}$ & $<\mathrm{LOQ}$ \\
\hline Benzo[a]anthracene & $\overline{14}$ & $\overline{9}$ & $\overline{12}$ & $<\mathrm{LOQ}$ & $<\mathrm{LOQ}$ & $<\mathrm{LOQ}$ \\
\hline Chrysene & $\underline{11}$ & $\underline{3}$ & $\underline{8}$ & $<\mathrm{LOQ}$ & $<$ LOQ & $<\mathrm{LOQ}$ \\
\hline Benzo $[b]$ fluoranthene & $<\overline{\mathrm{LOQ}}$ & $<\overline{L O Q}$ & $\underline{5}$ & $<\mathrm{LOQ}$ & $<\mathrm{LOQ}$ & $<\mathrm{LOQ}$ \\
\hline Benzo $[k]$ fluoranthene & $\underline{6}$ & $\underline{0,5}$ & $\underline{2}$ & $<\mathrm{LOQ}$ & $<\mathrm{LOQ}$ & $<\mathrm{LOQ}$ \\
\hline Benzo $[a]$ pyrene & $\underline{4}$ & $\underline{2}$ & $\overline{5}$ & $<\mathrm{LOQ}$ & $<\mathrm{LOQ}$ & $<\mathrm{LOQ}$ \\
\hline Dibenzo[ $a]$ anthracene & $\underline{0,8}$ & $<\overline{L O Q}$ & $\overline{1,3}$ & $<\mathrm{LOQ}$ & $<\mathrm{LOQ}$ & $<\mathrm{LOQ}$ \\
\hline Benzo[ghi]perylene & $\underline{5}$ & $<\mathrm{LOQ}$ & $\underline{7}$ & $<\mathrm{LOQ}$ & $<\mathrm{LOQ}$ & $<\mathrm{LOQ}$ \\
\hline$\Sigma 13$ PAHs & $\underline{255}$ & 131 & $7 \overline{3} 4$ & - & - & - \\
\hline
\end{tabular}




\section{CONCLUSIONS}

The contamination of various types of untreated and treated sewage sludges by a large panel of emerging pollutants $(\mathrm{n}=70)$ has been investigated in this paper. Parisian sludges, from two WWTPs treating wastewater from the same catchment, were considered in this paper, which represents $15 \%$ of the total mass (DM) of yearly sludge produced in France.

This study presents among the first data for several pharmaceutical compounds (PPHs), such as domperidone, lidocaine or tramadol. It also contributes to complete the database about sludge contamination for different groups of interesting pollutants (perfluorinated acids, phthalates, PAHs, LAS, alkylphenols and PCBs).

LAS are the predominant pollutants with contents ranging from few dozens to several thousands of $\mathrm{mg} / \mathrm{kg}$ DM. They are by far more concentrated than DEHP (10-100 mg $/ \mathrm{kg} \mathrm{DM})$, fluoroquinolones (1-100 mg/kg DM) and alkylphenols (APs; $2-20 \mathrm{mg} / \mathrm{kg}$ DM). Finally, the remaining compounds (PPHs, PFAs, PAHs, PCBs and PAEs) are less concentrated in sludges, with contents varying between 10 and $1000 \mu \mathrm{g} / \mathrm{kg}$ DM. In addition, a statistical analysis demonstrated the homogeneity of contents for most compounds in raw sludge from Seine Aval and Seine Centre, and in centrifuged sludge from Seine Centre and Seine Grésillons.

A simple and quick assessment of sludge contents allows highlighting the accumulation of some compounds in treated sludge, such as LAS, APs, PAHs, DEHP and PCBs. The increase of content results from dry matter and water removal coupled with a resistance of these compounds to treatment. In contrary, some compounds have lower contents in treated sludges, such as PPHs and PFAs, displaying a good propensity to be eliminated (more than dry matter). These results have to be confirmed by mass balances and flux calculations, and are the subject of a second article.

Then, this paper also presents interesting data of micropollutants in residual waters from two important sludge treatment processes: centrifugation and thermal drying. The presence of different types of molecules at relatively high concentrations in CW and TDW highlights the transfers that occur within the dissolved phase and the particles released from sludge during these processes. An extended investigation of this issue is realized in a second article, performing a complete analysis of removals and mass flux calculations.

\section{ACKNOWLEDGEMENTS}

This study has been conducted with the OPUR research program and the SIAAP supports. Authors would like to thank the SIAAP, LBE and ISA technical teams for their active participation in sampling and analyses.

\section{REFERENCES}

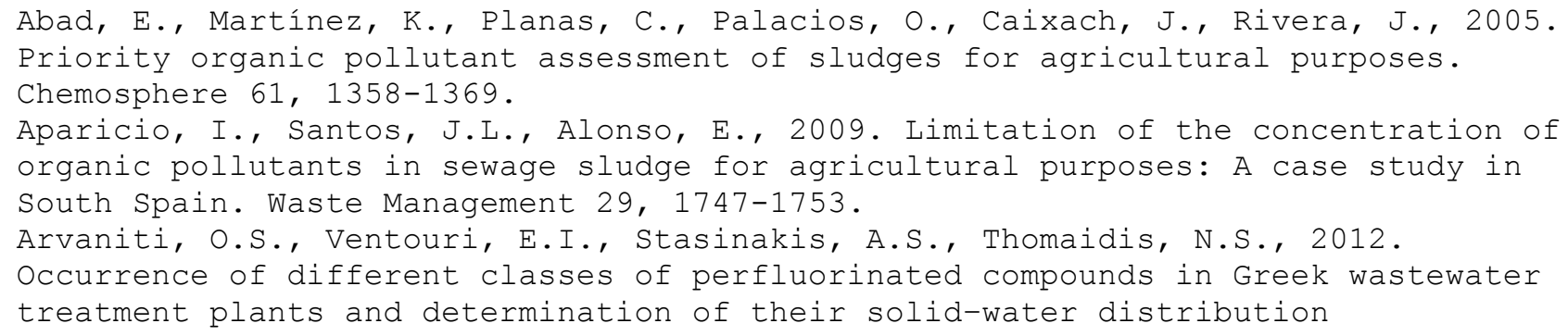


coefficients. Journal of Hazardous Materials 239-240, 24-31.

Bergé, A., Cladière, M., Gasperi, J., Coursimault, A., Tassin, B., Moilleron, R., 2012. Meta-analysis of environmental contamination by alkylphenols. Env Sci Poll Res Int 19, 3798-3819.

Bergé, A., Cladière, M., Gasperi, J., Coursimault, A., Tassin, B., Moilleron, R., 2013. Meta-analysis of environmental contamination by phthalates. Env Sci Poll Res Int, 1-20.

Besnault, S., Choubert, J.-M., Miège, C., Martin Ruel, S., Noyon, N., Esperanza, M., Budzinski, H., Le Menach, K., Dherret, L., Bados, P., Coquery, M., 2015 (submitted). Devenir des micropolluants adsorbables à travers les procédés de traitement des boues. Techniques Sciences et Méthodes.

Blanchard, M., Teil, M.J., Ollivon, D., Legenti, L., Chevreuil, M., 2004. Polycyclic aromatic hydrocarbons and polychlorobiphenyls in wastewaters and sewage sludges from the Paris area (France). Environmental Research 95, 184-197. Bossi, R., Strand, J., Sortkjær, O., Larsen, M.M., 2008. Perfluoroalkyl compounds in Danish wastewater treatment plants and aquatic environments. Environment International 34, 443-450.

Byrns, G., 2001. The fate of xenobiotic organic compounds in wastewater treatment plants. Water Research 35, $2523-2533$.

Cai, Q.-Y., Mo, C.-H., Wu, Q.-T., Zeng, Q.-Y., Katsoyiannis, A., 2007. Occurrence of organic contaminants in sewage sludges from eleven wastewater treatment plants, China. Chemosphere 68, 1751-1762.

Carballa, M., Manterola, G., Larrea, L., Ternes, T., Omil, F., Lema, J.M., 2007. Influence of ozone pre-treatment on sludge anaerobic digestion: Removal of pharmaceutical and personal care products. Chemosphere 67, 1444-1452.

Carballa, M., Omil, F., Lema, J.M., Llompart, M., Garcia-Jares, C., Rodriguez, I., Gomez, M., Ternes, T., 2004. Behavior of pharmaceuticals, cosmetics and hormones in a sewage treatment plant. Water Research 38, 2918-2926.

Chipasa, K.B., 2003. Accumulation and fate of selected heavy metals in a biological wastewater treatment system. Waste Management 23, 135-143.

Clara, M., Scharf, S., Scheffknecht, C., Gans, O., 2007. Occurrence of selected surfactants in untreated and treated sewage. Water Research 41, 4339-4348.

Clara, M., Windhofer, G., Hartl, W., Braun, K., Simon, M., Gans, O., Scheffknecht, C., Chovanec, A., 2010. Occurrence of phthalates in surface runoff, untreated and treated wastewater and fate during wastewater treatment. Chemosphere 78, 1078-1084.

Clarke, B.O., Smith, S.R., 2011. Review of 'emerging' organic contaminants in biosolids and assessment of international research priorities for the agricultural use of biosolids. Environment International 37, 226-247. Craig, P.J., 2003. Organometallic compounds in the environment. John Wiley \& Sons.

EC, 1986. Directive of the European Parliament and of the Council n ${ }^{\circ} 86 / 278 / \mathrm{EEC}$ establishing a framework for the community action in the field of sewage sludge policy. JO-EU L 181 .

EC, 1991. Directive of the European Parliament and of the Council n ${ }^{\circ}$ 91/271/EC establishing a framework for the community action in the field of sewage sludge policy. JO-EU L $135 / 40$.

EC, 2013. Directive 2013/39/EU of the European Parliament amending Directives 2000/60/EC and 2008/105/EC as regards priority substances in the field of water policy. JO-EU L226/1.

Ejlertsson, J., Nilsson, M.-L., Kylin, H., Bergman, Å., Karlson, L., Öquist, M. , Svensson, B.H., 1998. Anaerobic Degradation of Nonylphenol Mono- and Diethoxylates in Digestor Sludge, Landfilled Municipal Solid Waste, and Landfilled Sludge. Environmental Science \& Technology 33, 301-306.

Fytili, D., Zabaniotou, A., 2008. Utilization of sewage sludge in EU application of old and new methods-A review. Renewable and Sustainable Energy Reviews 12, 116-140.

Gasperi, J., Rocher, V., Gilbert, S., Azimi, S., Chebbo, G., 2010. Occurrence and removal of priority pollutants by lamella clarification and biofiltration. Water Research 44, 3065-3076.

Ghanem, A., Bados, P., Estaun, A.R., de Alencastro, L.F., Taibi, S., Einhorn, 
J., Mougin, C., 2007. Concentrations and specific loads of glyphosate, diuron, atrazine, nonylphenol and metabolites thereof in French urban sewage sludge. Chemosphere 69, 1368-1373.

Gibson, R.W., Wang, M.-J., Padgett, E., Beck, A.J., 2005. Analysis of 4nonylphenols, phthalates, and polychlorinated biphenyls in soils and biosolids. Chemosphere 61, 1336-1144.

Giger, W., Alder, A.C., Golet, E.M., Kohler, H.P.E., McArdell, C.S., Molnar, E., Siegrist, H., Suter, M.J.F., 2003. Occurrence and fate of antibiotics as trace contaminants in wastewaters, sewage sludges, and surface waters. Chimia 57, 485491.

Göbel, A., Thomsen, A., McArdell, C.S., Joss, A., Giger, W., 2005 . Occurrence and Sorption Behavior of Sulfonamides, Macrolides, and Trimethoprim in Activated Sludge Treatment. Environmental Science \& Technology 39, 3981-3989.

Golet, E.M., Xifra, I., Siegrist, H., Alder, A.C., Giger, W., 2003.

Environmental Exposure Assessment of Fluoroquinolone Antibacterial Agents from Sewage to Soil. Environmental Science \& Technology 37, 3243-3249.

González, M.M., Martín, J., Santos, J.L., Aparicio, I., Alonso, E., 2010. Occurrence and risk assessment of nonylphenol and nonylphenol ethoxylates in sewage sludge from different conventional treatment processes. Science of the Total Environment 408, 563-570.

Harrison, E.Z., Oakes, S.R., Hysell, M., Hay, A., 2006. Organic chemicals in sewage sludges. Science of the Total Environment 367, 481-497.

Heberer, T., 2002. Occurrence, fate, and removal of pharmaceutical residues in the aquatic environment: a review of recent research data. Toxicology Letters $131,5-17$.

Holt, M.S., Bernstein, S.L., 1992. Linear alkylbenzenes in sewage sludges and sludge amended soils. Water Research 26, 613-624.

Jia, A., Wan, Y., Xiao, Y., Hu, J., 2012. Occurrence and fate of quinolone and fluoroquinolone antibiotics in a municipal sewage treatment plant. Water

Research 46, 387-394.

Jones, V., Gardner, M., Ellor, B., 2014. Concentrations of trace substances in sewage sludge from 28 wastewater treatment works in the UK. Chemosphere 111, $478-484$.

Ju, J.-H., Lee, I.-S., Sim, W.-J., Eun, H., Oh, J.-E., 2009. Analysis and evaluation of chlorinated persistent organic compounds and PAHs in sludge in Korea. Chemosphere 74, 441-447.

Kelessidis, A., Stasinakis, A.S., 2012. Comparative study of the methods used for treatment and final disposal of sewage sludge in European countries. Waste Management 32, 1186-1195.

Li, W., Shi, Y., Gao, L., Liu, J., Cai, Y., 2013. Occurrence, distribution and potential affecting factors of antibiotics in sewage sludge of wastewater

treatment plants in China. Science of the Total Environment 445-446, 306-313. Lindberg, R.H., Olofsson, U., Rendahl, P., Johansson, M.I., Tysklind, M., Andersson, B.A.V., 2005a. Behavior of Fluoroquinolones and Trimethoprim during Mechanical, Chemical, and Active Sludge Treatment of Sewage Water and Digestion of Sludge. Environmental Science \& Technology 40, 1042-1048.

Lindberg, R.H., Wennberg, P., Johansson, M.I., Tysklind, M., Andersson, B.A.V., 2005b. Screening of Human Antibiotic Substances and Determination of Weekly Mass Flows in Five Sewage Treatment Plants in Sweden. Environmental Science \& Technology 39, 3421-3429.

Loganathan, B.G., Sajwan, K.S., Sinclair, E., Senthil Kumar, K., Kannan, K., 2007. Perfluoroalkyl sulfonates and perfluorocarboxylates in two wastewater treatment facilities in Kentucky and Georgia. Water Research 41, 4611-4620. Loos, R., Carvalho, R., António, D.C., Comero, S., Locoro, G., Tavazzi, S., Paracchini, B., Ghiani, M., Lettieri, T., Blaha, L., Jarosova, B., Voorspoels, S., Servaes, K., Haglund, P., Fick, J., Lindberg, R.H., Schwesig, D., Gawlik, B.M., 2013. EU-wide monitoring survey on emerging polar organic contaminants in wastewater treatment plant effluents. Water Research 47, 6475-6487.

Lu, J., Jin, Q., He, Y., Wu, J., Zhang, W., Zhao, J., 2008. Anaerobic degradation behavior of nonylphenol polyethoxylates in sludge. Chemosphere 71, $345-351$. 
Luo, Y., Guo, W., Ngo, H.H., Nghiem, L.D., Hai, F.I., Zhang, J., Liang, S., Wang, X.C., 2014. A review on the occurrence of micropollutants in the aquatic environment and their fate and removal during wastewater treatment. Science of the Total Environment 473-474, 619-641.

Mailler, R., Gasperi, J., Chebbo, G., Rocher, V., 2014a. Priority and emerging pollutants in sewage sludge and fate during sludge treatment. Waste Management $34,1217-1226$.

Mailler, R., Gasperi, J., Chebbo, G., Rocher, V., 2014b. Priority and emerging pollutants in sewage sludge and fate during sludge treatment. Waste Management. Mailler, R., Gasperi, J., Rocher, V., Gilbert-Pawlik, S., Geara-Matta, D., Moilleron, R., Chebbo, G., 2014c. Biofiltration vs conventional activated sludge plants: what about priority and emerging pollutants removal? Env Sci Poll Res Int 21, 5379-5390.

Moletta, R., 2008. Méthanisation de la biomasse (Biomass methanisation). Techniques de l'ingénieur (in French).

Muller, M., Combalbert, S., Delgenès, N., Bergheaud, V., Rocher, V., Benoît, P., Delgenès, J.-P., Patureau, D., Hernandez-Raquet, G., 2010. Occurrence of estrogens in sewage sludge and their fate during plant-scale anaerobic digestion. Chemosphere 81, 65-71.

Muller, M., Patureau, D., Balaguer, P., Delgenes, N., Dagnino, S., Delgenes, J.P., Hernandez-Raquet, G., 2007. Assessment of estrogenic and xenobiotic receptor activities in combination with chemical analysis of micropollutants during wastewater biosolids composting, Wastewater Biosolids Sustainability: Technical, Managerial, and Public Synergy, Moncton, New Brunswick, Canada. Narumiya, M., Nakada, N., Yamashita, N., Tanaka, H., 2013. Phase distribution and removal of pharmaceuticals and personal care products during anaerobic sludge digestion. Journal of Hazardous Materials 260, 305-312.

Neyens, E., Baeyens, J., 2003. A review of thermal sludge pre-treatment processes to improve dewaterability. Journal of Hazardous Materials 98, 51-67. Nie, Y., Qiang, Z., Zhang, H., Adams, C., 2009. Determination of endocrinedisrupting chemicals in the liquid and solid phases of activated sludge by solid phase extraction and gas chromatography-mass spectrometry. Journal of Chromatography A 1216, 7071-7080.

Nieto, A., Borrull, F., Pocurull, E., Marce, R.M., 2010. Occurrence of pharmaceuticals and hormones in sewage sludge. Environmental toxicology and chemistry / SETAC 29, 1484-1489.

Olofsson, U., Bignert, A., Haglund, P., 2012. Time-trends of metals and organic contaminants in sewage sludge. Water Research 46, 4841-4851.

Pakou, C., Kornaros, M., Stamatelatou, K., Lyberatos, G., 2009. On the fate of LAS, NPEOS and DEHP in municipal sewage sludge during composting. Bioresource Technology 100, 1634-1642.

Patureau, D., Delgenes, N., Muller, M., Dagnino, S., Lhoutellier, C., Delgenes, J.-P., Balaguer, P., Hernandez-Raquet, G., 2012. Chemical and toxicological assessment of a full-scale biosolid compost. Environmental Toxicology and Chemistry 31, 2748-2756.

Peysson, W., Vulliet, E., 2013. Determination of 136 pharmaceuticals and hormones in sewage sludge using quick, easy, cheap, effective, rugged and safe extraction followed by analysis with liquid chromatography-time-of-flight-mass spectrometry. Journal of Chromatography A 1290, 46-61.

Radjenović, J., Petrović, M., Barceló, D., 2009. Fate and distribution of pharmaceuticals in wastewater and sewage sludge of the conventional activated sludge (CAS) and advanced membrane bioreactor (MBR) treatment. Water Research $43,831-841$.

Ruel, S.M., Choubert, J.M., Budzinski, H., Miege, C., Esperanza, M., Coquery, M., 2012. Occurrence and fate of relevant substances in wastewater treatment plants regarding Water Framework Directive and future legislations. Water Science and Technology 65, 1179-1189.

Samaras, V.G., Stasinakis, A.S., Mamais, D., Thomaidis, N.S., Lekkas, T.D., 2013. Fate of selected pharmaceuticals and synthetic endocrine disrupting compounds during wastewater treatment and sludge anaerobic digestion. Journal of Hazardous Materials 244-245, 259-267. 
Schultz, M.M., Higgins, C.P., Huset, C.A., Luthy, R.G., Barofsky, D.F., Field, J.A., 2006. Fluorochemical Mass Flows in a Municipal Wastewater Treatment Facility. Environmental Science \& Technology 40, 7350-7357.

Sinclair, E., Kannan, K., 2006. Mass Loading and Fate of Perfluoroalkyl Surfactants in Wastewater Treatment Plants. Environmental Science \& Technology 40, 1408-1414.

Stasinakis, A.S., Thomaidis, N.S., Arvaniti, O.S., Asimakopoulos, A.G., Samaras, V.G., Ajibola, A., Mamais, D., Lekkas, T.D., 2013. Contribution of primary and secondary treatment on the removal of benzothiazoles, benzotriazoles, endocrine disruptors, pharmaceuticals and perfluorinated compounds in a sewage treatment plant. Science of the Total Environment 463-464, 1067-1075.

Stevens, J.L., Northcott, G.L., Stern, G.A., Tomy, G.T., Jones, K.C., 2002. PAHs, PCBs, PCNs, Organochlorine Pesticides, Synthetic Musks, and

Polychlorinated n-Alkanes in U.K. Sewage Sludge: Survey Results and

Implications. Environmental Science \& Technology 37, 462-467.

Subedi, B., Lee, S., Moon, H.-B., Kannan, K., 2014. Emission of artificial

sweeteners, select pharmaceuticals, and personal care products through sewage sludge from wastewater treatment plants in Korea. Environment International 68, 33-40.

Valo, A., Carrère, H., Delgenès, J.P., 2004. Thermal, chemical and thermochemical pre-treatment of waste activated sludge for anaerobic digestion. Journal of Chemical Technology \& Biotechnology 79, 1197-1203.

Verlicchi, P., Al Aukidy, M., Zambello, E., 2012. Occurrence of pharmaceutical compounds in urban wastewater: Removal, mass load and environmental risk after a secondary treatment-A review. Science of the Total Environment 429, 123-155.

Voulvoulis, N., Lester, J.N., 2006. Fate of organotins in sewage sludge during anaerobic digestion. Science of the Total Environment 371, 373-382.

Zeng, L., Wang, T., Ruan, T., Liu, Q., Wang, Y., Jiang, G., 2012. Levels and distribution patterns of short chain chlorinated paraffins in sewage sludge of wastewater treatment plants in China. Environmental Pollution 160, 88-94.

Zeng, X., Lin, Z., Gui, H., Shao, W., Sheng, G., Fu, J., Yu, Z., 2010.

occurrence and distribution of polycyclic aromatic carbons in sludges from wastewater treatment plants in Guangdong, China. Environ Monit Assess 169, 89100 .

Zhou, X., Zhang, Y., Shi, L., Chen, J., Qiang, Z., Zhang, T.C., 2013.

Partitioning of Fluoroquinolones on Wastewater Sludge. CLEAN - Soil, Air, Water $41,820-827$. 